\title{
Potencial das atividades de uso público do Núcleo Picinguaba do Parque Estadual da Serra do Mar (SP) para uma educação ambiental crítica
}

\author{
Potential of public use activities in Picinguaba Nucleus \\ of the Serra do Mar State Park (SP) \\ towards a critical environmental education
}

\author{
Mayla Willik Valenti ${ }^{1}$. Valéria Ghisloti Iared ${ }^{2}$. \\ Haydée Torres de Oliveira ${ }^{3}$
}

\begin{abstract}
Resumo: O foco desse trabalho foi o Subprograma de Educação Ambiental do Núcleo Picinguaba do Parque Estadual da Serra do Mar. Realizamos observação participante de atividades de uso público, com estudantes universitários, utilizando um roteiro prévio e anotações de caderno de campo. A coleta de dados considerou parâmetros relacionados às dimensões dos conhecimentos, dos valores éticos e estéticos e da participação política. Analisamos os dados encontrados de acordo com as diferentes tendências da educação ambiental. Como resultados, encontramos a predominância da tendência crítica da educação ambiental na maioria dos parâmetros analisados. Em relação à participação política, notamos que vários temas que poderiam ter sido abordados foram silenciados. No entanto, ainda assim, concluímos que há um grande potencial das unidades de conservação para desenvolver ações de educação ambiental de forma crítica, reflexiva e dialógica.
\end{abstract}

Palavras-chave: Educação ambiental. Área protegida. Unidade de conservação. Parque Estadual Serra do Mar.

\begin{abstract}
This study focus on the Environmental Education Sub-program of Picinguaba Nucleus of the Serra do Mar State Park. We performed participative observations of the public using activities with university students, using a preview guide and field notes. Data collection was conducted considering the parameters related to the dimensions of knowledge, ethical and aesthetic values and political participation. We analyzed data according to the different tendencies of environmental education. As results, we found a predominance of the critical tendency of environmental education in the most of analyzed parameters. In relation to political participation, we noticed that many topics that could have been addressed were silent. Nevertheless, we identified a high potential of the protected areas to develop critical, reflexive and dialogical environmental education actions.
\end{abstract}

Keywords: Enviromental education. Conservation unit. Protected area. Parque Estadual Serra do Mar.

\footnotetext{
${ }^{1,2,3}$ Departamento de Ciências Ambientais, Universidade Federal de São Carlos (UFSCar), Rod. Washington Luís, km 235, Monjolinho, CEP 13565-905, São Carlos, SP, Brasil. E-mail: <maylabio@yahoo.com.br>.
} 


\section{Introdução}

As ações de educação ambiental contribuem para a conservação da biodiversidade por proporcionarem novas relações com a natureza e com a sociedade (MENDONÇA, 2005), e a ação diante dos problemas ambientais (HAMÚ; AUCHINCLOSS; GOLDSTEIN, 2004). Nesse sentido, áreas naturais protegidas, como as unidades de conservação, são privilegiadas para a atuação em educação ambiental, especialmente sobre o tema biodiversidade (SAMMARCO, 2005). Segundo Carvalho (2006), a educação ambiental deve se pautar em três dimensões: a natureza dos conhecimentos, os valores éticos e estéticos, e a participação política. A primeira dimensão é fundamental para se compreender a complexidade dos componentes e processos naturais, e como tais fatores estão intrinsecamente associados ao contexto histórico das civilizações humanas. A segunda dimensão atua no âmbito da sensibilização e do respeito em relação ao ambiente, em seu conceito amplo, para a revisão das posturas e dos padrões vigentes. A terceira dimensão trabalha o exercício da cidadania, isto é, está relacionada à relevância de a sociedade se organizar em um coletivo que reflita, construa e reivindique, possibilitando uma efetiva atuação política.

Contudo, o campo da educação ambiental não é homogêneo no que se refere a perspectivas teórico-metodológicas e pressupostos político-pedagógicos, o que se reflete na prática educativa (CARVALHO, 2006; SAUVÉ, 2005a, 2005b; TOZONI-REIS, 2004). Dessa maneira, o trabalho com as dimensões dos conhecimentos, valores éticos e estéticos e participação política propostas por Carvalho (2006) varia de acordo com essas perspectivas. Considerando essa diversidade de abordagens, Marpica (2008) propôs uma classificação em quatro tendências da educação ambiental, com base em Silva (2007), Grün (1996) e outras/os autoras/es ${ }^{4}$ :

a) Tendência silenciosa: refere-se a momentos ou assuntos que seriam oportunos para trabalhar certas questões ambientais e, no entanto, elas não aparecem nem ao menos implicitamente.

b) Tendência conservacionista: o ser humano não é visto como parte da natureza. Prevalece uma visão contemplativa da natureza e as questões ambientais são apresentadas de forma superficial, com enfoque para aspectos biológicos. Os conhecimentos locais, o contexto histórico, a diversidade cultural e a interdisciplinaridade são desconsiderados; a tecnologia é tida como a causa dos problemas ambientais, e o futuro do planeta como dependente de indivíduos conscientes da gravidade da situação.

c) Tendência pragmática: assim como a conservacionista, as questões ambientais são discutidas superficialmente, mas a ciência e a tecnologia não são consideradas como causa, mas como solução para os problemas ambientais. A natureza é vista como recurso, e apenas medidas normativas e punitivas poderão ser eficientes contra a degradação do ambiente.

d) Tendência crítica: considera o contexto histórico, cultural, político e social dos conflitos ambientais, que devem ser discutidos até suas raízes para a compreensão e superação

\footnotetext{
${ }^{4}$ Seguindo a indicação de Freire (1994), em "Pedagogia da esperança", e as Diretrizes para uma linguagem não sexista da UNESCO (CASELLATO; HOLZHACKER; FERNANDEZ, 1996), optamos por nos referir sempre aos dois gêneros ao longo do artigo, como uma forma de romper com a dominância do gênero masculino no texto escrito e, assim, adotar uma linguagem não sexista.
} 
dos problemas. Valoriza os conhecimentos tradicionais e os científicos, na tentativa de buscar soluções para os danos ao ambiente. O diálogo é tido como um dos princípios da educação ambiental, o movimento coletivo e a atuação política são pressupostos básicos para a emergência de um novo paradigma.

Segundo Pacheco-Muñoz (2002), muitas áreas naturais têm programas de educação ambiental centrados apenas em aspectos de gestão, voltando a atenção para a quantidade de espécies presentes na área e o manejo das mesmas, caracterizando tendências conservacionistas ou pragmáticas da educação ambiental. Nesse sentido, a presença da biodiversidade conservada nas áreas naturais não é sinônimo de um programa de educação ambiental eficiente. Portanto, temas como extinção de espécies, ecologia, evolução, as consequências sociais da perda da biodiversidade, legislação, saúde, segurança ambiental, biotecnologia, serviços ambientais, conhecimentos tradicionais e os problemas ambientais em todas as suas esferas (políticas, econômicas, sociais e culturais) poderiam ser amplamente discutidos nesses programas (PACHECO-MUÑOZ, 2002).

Por outro lado, muitas/os autoras/es têm destacado avanços teóricos, práticos e nas políticas públicas, no sentido de superar as tendências mais conservadoras da educação ambiental em busca de uma proposta que abarque a complexidade das questões socioambientais, trabalhando-a com abordagens críticas, reflexivas, participativas, dialógicas e solidárias (BARBOSA, 2008; LOUREIRO, 2004a; SILVEIRA, 2009; SORRENTINO; FERRARO-JÚNIOR; MARCON, 2007; SORRENTINO et al., 2007; TRISTÃO, 2005). Nas unidades de conservação, essa perspectiva tem sido bastante utilizada em ações com as comunidades que vivem dentro ou no entorno dessas áreas, envolvendo-as em processos de gestão participativa das unidades (FRANCA, 2006; LAYRARGUES, 2000, 2002; LOUREIRO, 2004a; MADUREIRA; TAGLIANI, 1997; QUINTAS, 2002, 2004; SAMMARCO, 2009). Entretanto, esses espaços recebem, com muita frequência, um grande número de visitantes, sejam turistas, estudantes ou pesquisadoras/es. Essas pessoas passam relativamente pouco tempo nas unidades de conservação, mas, por geralmente viverem em ambientes urbanos, essas visitas são uma das poucas oportunidades de contato com ambientes naturais oferecidas a elas. Porém, existem poucos trabalhos que discutem a abordagem crítica da educação ambiental nos programas de uso público das unidades de conservação.

Assim, este estudo pretende incentivar e contribuir com essa discussão. Para tanto, optamos por investigar a presença de diferentes tendências da educação ambiental em atividades realizadas no Núcleo Picinguaba do Parque Estadual da Serra do Mar, relacionando-as a parâmetros das três dimensões da prática educativa: conhecimentos, valores éticos e estéticos, e participação política. Além disso, buscamos identificar diferenças de abordagens em relação a diferentes tipos de atividade e de guias. A partir destes dados, indicamos o potencial das unidades de conservação para o desenvolvimento de uma educação ambiental crítica em seus programas de uso público.

\section{Procedimentos metodológicos}

O Parque Estadual da Serra do Mar (PESM) foi delimitado com uma área de 315.390 hectares em 1970, e corresponde à maior área de proteção integral do litoral brasileiro. O presente estudo tem seu foco no Núcleo Picinguaba, que foi incorporado ao parque somente em 1979 e, atualmente, constitui um dos oito núcleos administrativos da unidade de conservação. 
O Núcleo Picinguaba está localizado no município de Ubatuba (SP) e abrange uma área onde se encontram mangues, restingas e praias, sendo o único núcleo da unidade no qual a proteção atinge a cota zero do nível do mar (SÃO PAULO, 2006).

Em 1997, intensificaram-se os esforços para a elaboração do plano de manejo dessa unidade de conservação, o qual foi publicado em fevereiro de 2006 (SÃO PAULO, 2006). Nele são descritas: a história, a justificativa, as características sociais, ambientais e econômicas do PESM. Por meio da elaboração e planejamento participativos, foram propostas diretrizes, estratégias, ações e atividades organizadas em programas de manejo (SÃO PAULO, 2006). Um desses programas é o de Uso Público, o qual é subdividido em Subprograma de Visitação e Turismo Sustentável e Subprograma de Educação Ambiental, que foi o foco dessa investigação.

Realizamos a coleta de dados durante três dias, em junho de 2008. Nesse período, acompanhamos diferentes atividades educativas realizadas para grupos de estudantes de graduação e pós-graduação. As pesquisadoras atuaram como observadoras participantes, pois faziam parte do grupo de visitantes e, ao mesmo tempo, foram a campo com o intuito de coletar dados para esta pesquisa. Em alguns momentos, o mesmo grupo de visitantes foi dividido, sendo guiado por diferentes monitores. Nesses casos, cada pesquisadora acompanhou a mesma atividade guiada por monitores diferentes. Para a apresentação dos resultados, atribuímos, como símbolo, as iniciais de cada atividade observada e um número, referente à pesquisadora 1 e à pesquisadora 2. A seguir, elencamos as atividades, suas descrições e a maneira como foram observadas e registradas:

- Palestra Inicial (PI): o monitor apresentou características ecológicas, geográficas, políticas e culturais relacionadas à unidade de conservação. Essa atividade foi conduzida por um monitor e observada por duas pesquisadoras.

- Trilha dos Poços (TP): o grupo percorreu um trajeto com vegetação de Mata Atlântica, um córrego com poços e cachoeiras, e visitou uma comunidade quilombola residente no local. Essa trilha foi observada por duas/ois pesquisadoras/es guiadas/os por monitores diferentes.

- Trilha do Manguezal (TM): foram visitadas uma área de restinga alagada, com grande influência antrópica, uma floresta de restinga conservada, e um ecossistema de manguezal. Essa trilha foi conduzida por um monitor e observada por duas pesquisadoras.

- Roda de Conversa (RC): consistiu em um bate-papo informal com um membro de uma comunidade local que vive dentro do parque, e foi acompanhado por duas investigadoras.

O trabalho foi desenvolvido com um caráter qualitativo (DENZIN; LINCOLN, 2003), já que enfatizamos as qualidades e significados observados, buscando indicar o potencial das unidades de conservação para desenvolverem programas de uso público com base na educação ambiental crítica. No processo de investigação, as subjetividades das pesquisadoras foram consideradas, e não se pretendeu a neutralidade na interpretação dos dados, visto que não consideramos isto possível em qualquer investigação. Contudo, o registro dos dados foi feito de forma rigorosa, procurando, ao máximo, retratar a realidade observada. Para registrar as observações, realizamos anotações em caderno de campo, seguindo um roteiro prévio. Posteriormente, para cada atividade observada, preenchemos um roteiro de análise contendo parâmetros relacionados a cada dimensão da prática educativa.

O roteiro de análise foi elaborado com base no trabalho de Marpica (2008), que analisou tendências da educação ambiental em livros didáticos. Marpica (2008) propôs parâmetros para análise das tendências da educação ambiental em cada dimensão proposta por Carvalho (2006) com base na literatura da área. Adaptamos a ferramenta de análise feita pela autora ao contexto 
das unidades de conservação, com base no trabalho de Wals (1999), que propõe conteúdos e procedimentos a serem trabalhados em ações de educação ambiental com o tema da biodiversidade. Desde modo, na dimensão dos conhecimentos, analisamos os seguintes parâmetros: conceito de biodiversidade, inter e transdisciplinaridade, papel do conhecimento local e contextualizações da questão ambiental. $\mathrm{Na}$ dimensão dos valores éticos e estéticos, avaliamos os parâmetros: valores da biodiversidade, relações ser humano-natureza, abordagem dos conflitos, diferenças no acesso aos recursos ambientais e nos riscos dos impactos ambientais, o papel da solidariedade e da competitividade, a forma de apresentação dos pontos de vista, experiência estética e uso de elementos estéticos. Já na dimensão da participação política consideramos os parâmetros: discussão sobre legislação ambiental, responsabilização pelas causas da crise ambiental, responsabilização pela busca de soluções, discussão sobre o ideal de sociedade sustentável, papel da educação para a conservação ambiental, soluções de ordem social relacionadas à conservação, e conceito de cidadania. A descrição detalhada de cada parâmetro segundo cada tendência da educação ambiental analisada pode ser encontrada em Marpica (2008) e Valenti (2010).

Ao preenchermos o roteiro de análise, classificamos cada parâmetro nas quatro tendências da educação ambiental: silenciosa, conservacionista, pragmática e crítica. As descrições de cada parâmetro em cada tendência, nas quais este trabalho foi baseado, são apresentadas em Marpica (2008). Assumimos que a classificação de tendências da educação ambiental é apenas uma tentativa de compreensão desse campo do conhecimento e que, na prática, as tendências não são mutuamente exclusivas em todos os aspectos (SAUVÉ, 2005a). Assim, quando identificamos características de mais de uma tendência para determinado parâmetro, atribuímos a classificação de todas as tendências observadas para o mesmo.

Para analisar as ações de educação ambiental realizadas no Núcleo Picinguaba, ponderamos a tendência predominante para cada atividade observada e cada parâmetro analisado. Do mesmo modo, verificamos a tendência predominante em cada dimensão (conhecimentos, valores éticos e estéticos e participação política) e, de forma geral, considerando as três dimensões da prática educativa.

\section{Resultados e discussão}

Nas atividades observadas no Núcleo Picinguaba do Parque Estadual da Serra do Mar, a tendência crítica predominou em praticamente todos os parâmetros relacionados à dimensão dos conhecimentos (Quadro 1). Um dos parâmetros analisados foi o conceito de biodiversidade. Morello e Pengue (2000) apresentam a biodiversidade como uma propriedade dos sistemas vivos e culturais. Partindo desse pressuposto, esse conceito deve ser encarado de forma ampla, incorporando os aspectos sociológicos relacionados ao mesmo (OLIVEIRA, 2004). Nas atividades que observamos, a importância da diversidade cultural foi ressaltada em diversos momentos. Além disso, os saberes tradicionais foram valorizados e as situações foram apresentadas em seus contextos históricos, econômicos e sociais, caracterizando a tendência crítica da educação ambiental. Apenas o parâmetro 'relação da ciência e tecnologia com o tema ambiental' apresentou a tendência silenciosa como predominante, ou seja, foi pouco abordado.

$\mathrm{Na}$ dimensão dos valores éticos e estéticos também predominou a tendência crítica (Quadro 2). A discussão sobre os conflitos da presença das comunidades tradicionais na unidade de conservação de proteção integral, durante as atividades, contribuiu consideravelmente 
para esse resultado. Proteção Integral é a categoria de Unidade de Conservação (UC) na qual o objetivo básico é preservar a natureza, ou seja, não é permitida a presença de moradores, sendo admitido apenas o uso indireto dos seus recursos naturais (SISTEMA..., 2004). A contextualização e problematização das causas dos conflitos parecem delinear um bom potencial para compreensão e reflexão da complexidade do ambiente. De forma semelhante, Marpica (2008), em sua análise sobre livros didáticos, verificou que o livro de história foi o que mais apresentou trechos com tendência crítica. Segundo Carvalho (1989 apud CARVALHO, 2006, p. 38), o debate de temas controversos é uma boa opção para desvelar a ideia de um "consenso aparente". Nesse sentido, García-Gómez e Nando-Rosales (2000) sugerem que a questão de valores seja

Quadro 1. Predominância das tendências da educação ambiental em atividades desenvolvidas no Núcleo Picinguaba do Parque Estadual da Serra do Mar, relacionada à dimensão dos conhecimentos

\begin{tabular}{|l|c|c|c|}
\hline \multicolumn{1}{|c|}{ Atividades/Parâmetros } & PI1 & PI2 & TP1 \\
\hline Conceito de biodiversidade & Crítica & Crítica & Crítica \\
\hline Inter e transdisciplinaridade & Crítica & Crítica & Conservacionista \\
\hline Papel do conhecimento local & Crítica & Crítica & Crítica \\
\hline Contextualizações da questão ambiental & Crítica & Crítica & Crítica \\
\hline Papel da ciência e tecnologia & Conservacionista & Silenciosa & Silenciosa \\
\hline Predominância & Crítica & Crítica & Crítica \\
\hline \multicolumn{1}{|c|}{ Atividades/Parâmetros } & TP2 & TM1 & TM2 \\
\hline Conceito de biodiversidade & Crítica & Crítica & Crítica \\
\hline Inter e transdisciplinaridade & Crítica & Crítica & Crítica \\
\hline Papel do conhecimento local & Crítica & Crítica & Crítica \\
\hline Contextualizações da questão ambiental & Crítica & Crítica & Crítica \\
\hline Papel da ciência e tecnologia & Crítica & Conservacionista & Silenciosa \\
\hline Predominância & Crítica & Crítica & Crítica \\
\hline \multicolumn{1}{|c|}{ Atividades/Parâmetros } & RC1 & RC2 & Total \\
\hline Conceito de biodiversidade & Crítica & Conservacionista & Crítica \\
\hline Inter e transdisciplinaridade & Conservacionista & Silenciosa & Crítica \\
\hline Papel do conhecimento local & Crítica & Crítica & Crítica \\
\hline Contextualizações da questão ambiental & Crítica & Crítica & Crítica \\
\hline Papel da ciência e tecnologia & Silenciosa & Silenciosa \\
\hline Predominância & Crítica & Crítica \\
\hline
\end{tabular}

PI1 e 2 = palestra inicial; TP1 = trilha dos poços guiada por monitor 1 ; TP2 $=$ trilha dos poços guiada por monitor 2; TM1 e 2 = trilha do manguezal; RC1 e 2 = roda de conversa; todas as atividades observadas por pesquisadoras 1 e 2 , respectivamente).

Fonte: elaborado pelas autoras. 
contemplada nos espaços de aprendizagem quando novos elementos, antes desconhecidos, são apontados durante a discussão. Nesse momento, os vários argumentos e opiniões do grupo auxiliam na reconstrução do referencial de valores. A discussão, durante a visita, sobre uma série de conflitos que perpassam pela unidade de conservação, nos quais não há certo e errado ou bom e mal, é algo que contribui muito para a reformulação das visões das/os visitantes, fato refletido na observação da tendência crítica em muitos parâmetros dessa dimensão.

Os parâmetros relacionados aos valores estéticos foram frequentemente silenciados e o 'uso de elementos estéticos' foi o único parâmetro analisado que não recebeu nenhum apontamento da tendência crítica. De forma geral, os valores estéticos são pouco trabalhados em ações de educação ambiental (BONOTTO, 2008; CARR, 2004; IARED; OLIVEIRA, 2012;

Quadro 2. Predominância das tendências da educação ambiental em atividades desenvolvidas no Núcleo Picinguaba do Parque Estadual da Serra do Mar, relacionada à dimensão dos valores éticos e estéticos

\begin{tabular}{|l|c|c|c|}
\hline \multicolumn{1}{|c|}{ Atividades/Parâmetros } & PI1 & PI2 & TP1 \\
\hline Valores da biodiversidade & Crítica & $\begin{array}{c}\text { Conservacionista } \\
\text { Crítica }\end{array}$ & Pragmática \\
\hline Relações ser humano-natureza & Crítica & Crítica & $\begin{array}{c}\text { Conservacionista }+ \\
\text { Pragmática }\end{array}$ \\
\hline Abordagem dos conflitos & Crítica & Crítica & $\begin{array}{c}\text { Pragmática }+ \\
\text { Crítica }\end{array}$ \\
\hline Diferenças no acesso e riscos & Crítica & Crítica & Silenciosa \\
\hline Solidariedade e competitividade & Silenciosa & Crítica & Silenciosa \\
\hline Apresentação de pontos de vista & Crítica & Crítica & Crítica \\
\hline Experiência estética & Silenciosa & Silenciosa & Silenciosa \\
\hline Uso de elementos estéticos & Pragmática & Pragmática & Silenciosa \\
\hline Predominância & Crítica & Crítica & Silenciosa \\
\hline \multicolumn{1}{|c|}{ Atividades/Parâmetros } & TP2 & TM1 & TM2 \\
\hline Valores da biodiversidade & Crítica & Conservacionista & Crítica \\
\hline Relações ser humano-natureza & Crítica & Crítica & Crítica \\
\hline Abordagem dos conflitos & Crítica & Crítica & Crítica \\
\hline Diferenças no acesso e riscos & Crítica & Crítica & Crítica \\
\hline Solidariedade e competitividade & Conservacionista & Silenciosa & Conservacionista + \\
\hline Apresentação de pontos de vista & Crítica & Silenciosa & Silenciosa \\
\hline Experiência estética & Crítica & Silenciosa & Crítica \\
\hline Uso de elementos estéticos & Conservacionista & Silenciosa & Conservacionista \\
\hline Predominância & Crítica & Silenciosa & Crítica \\
\hline
\end{tabular}


Quadro 2. continuação

\begin{tabular}{|l|c|c|c|}
\hline \multicolumn{1}{|c|}{ Atividades/Parâmetros } & RC1 & RC2 & Total \\
\hline Valores da biodiversidade & Crítica & Crítica & Crítica \\
\hline Relações ser humano-natureza & Crítica & Crítica & Crítica \\
\hline Abordagem dos conflitos & Pragmática & Pragmática & Crítica \\
\hline Diferenças no acesso e riscos & Crítica & Crítica & Crítica \\
\hline Solidariedade e competitividade & Silenciosa & Conservacionista + & Crítica \\
\hline Apresentação de pontos de vista & Crítica & Crítica & Silenciosa \\
\hline Experiência estética & Silenciosa & Crítica & Silenciosa + \\
\hline Uso de elementos estéticos & Silenciosa & Conservacionista & Conservacionista \\
\hline Predominância & & Crítica & Crítica \\
\hline
\end{tabular}

PI1 e 2 = palestra inicial; TP1 = trilha dos poços guiada por monitor $1 ;$ TP2 $=$ trilha dos poços guiada por monitor 2; TM1 e 2 = trilha do manguezal; RC1 e 2 = roda de conversa; todas as atividades observadas por pesquisadoras 1 e 2 , respectivamente.

Fonte: elaborado pelas autoras.

LAÇİN ŞİMŞEK, 2011). Estes estudos apresentam uma preocupação com a falta de abordagem sobre as questões estéticas da natureza quando apontam a importância de se recuperar diferentes possibilidades de experiência estética.

Os elementos estéticos foram apresentados de forma bucólica e nostálgica, caracterizando a tendência conservacionista; ou de forma puramente ilustrativa, caracterizando a tendência pragmática. Carvalho (2001) e Iared e Oliveira (2013) identificaram que a imersão na natureza em um caráter mais lúdico e espontâneo são fatores importantes para estabelecimento de um vínculo afetivo com o ambiente. Dessa maneira, as autoras indicam que poderíamos resgatar alguns aspectos da educação ambiental conservacionista para compor os elementos da educação ambiental crítica em que nos pautamos. Segundo Seniciato e Cavassan (2009) e Silveira (2009), a experiência estética pressupõe que a/o espectador/a se coloque em uma postura ativa ao perceber o mundo, sem se limitar a interpretá-lo com conceitos racionais. Dessa maneira, requer uma mudança da postura pragmática de perceber a realidade, e provoca uma reflexão sobre o próprio sujeito participante da experiência e as relações que este traça com o ambiente, caracterizando uma perspectiva crítica da educação ambiental. De fato, áreas naturais são locais indicados por diversas/os autoras/es para o desenvolvimento de estratégias de sensibilização que despertem esse respeito para com a natureza (LIMA, 1998; MARIN; OLIVEIRA; COMAR, 2003; MENDONÇA, 2007; MENDONÇA; NEIMAN, 2003; MENGHINI; MOYÁ-NETO; GUERRA, 2007; SENICIATO; CAVASSAN, 2009). Logo, o Núcleo Picinguaba, assim como todas as unidades de conservação, tem uma grande potencialidade para trabalhar com elementos e experiências estéticas em suas atividades de educação ambiental.

$\mathrm{Na}$ esfera da participação política, predominou a tendência silenciosa, indicando que esse aspecto é o menos trabalhado nas atividades observadas (Quadro 3). Apesar disso, a ten- 
Quadro 3. Predominância das tendências da educação ambiental em atividades desenvolvidas no Núcleo Picinguaba do Parque Estadual da Serra do Mar, relacionada à dimensão da participação política

\begin{tabular}{|c|c|c|c|}
\hline Atividades/Parâmetros & PI1 & PI2 & TP1 \\
\hline Discussão sobre legislação ambiental & Crítica & Crítica & Silenciosa \\
\hline Responsabilização pelas causas da crise ambiental & Crítica & Crítica & Silenciosa \\
\hline Responsabilização pela busca de soluções & Crítica & Crítica & Silenciosa \\
\hline Discussão sobre o ideal de sociedade sustentável & Crítica & Crítica & Silenciosa \\
\hline Papel da educação para a conservação ambiental & Crítica & Crítica & Silenciosa \\
\hline Soluções de ordem social relacionadas à conservação & Crítica & Crítica & Crítica \\
\hline Conceito de cidadania & Crítica & Crítica & Silenciosa \\
\hline Predominância & Crítica & Crítica & Silenciosa \\
\hline Atividades/Parâmetros & TP2 & TM1 & TM2 \\
\hline Discussão sobre legislação ambiental & Crítica & Silenciosa & Crítica \\
\hline Responsabilização pelas causas da crise ambiental & Silenciosa & Crítica & Crítica \\
\hline Responsabilização pela busca de soluções & Crítica & Silenciosa & Silenciosa \\
\hline Discussão sobre o ideal de sociedade sustentável & Crítica & Silenciosa & Silenciosa \\
\hline Papel da educação para a conservação ambiental & Crítica & Silenciosa & Silenciosa \\
\hline Soluções de ordem social relacionadas à conservação & Crítica & Crítica & Silenciosa \\
\hline Conceito de cidadania & Crítica & Silenciosa & Silenciosa \\
\hline Predominância & Crítica & Silenciosa & Silenciosa \\
\hline Atividades/Parâmetros & RC1 & RC2 & Total \\
\hline Discussão sobre legislação ambiental & Silenciosa & Silenciosa & Silenciosa + Crítica \\
\hline Responsabilização pelas causas da crise ambiental & Crítica & Silenciosa & Crítica \\
\hline Responsabilização pela busca de soluções & Crítica & Silenciosa & Silenciosa + Crítica \\
\hline Discussão sobre o ideal de sociedade sustentável & Silenciosa & Silenciosa & Silenciosa \\
\hline Papel da educação para a conservação ambiental & Silenciosa & Silenciosa & Silenciosa \\
\hline Soluções de ordem social relacionadas à conservação & Crítica & Silenciosa & Crítica \\
\hline Conceito de cidadania & Silenciosa & Crítica & Silenciosa + Crítica \\
\hline Predominância & Silenciosa & Silenciosa & Silenciosa \\
\hline
\end{tabular}

dência crítica foi observada para diversos parâmetros em atividades diferentes, indicando que é possível incluir conteúdos relacionados à participação e cidadania nas visitas às unidades de conservação. Carvalho (2006) atenta para o fato de que as ações educativas devem sinalizar 
para uma direção de rupturas profundas com os padrões de desenvolvimento vigentes, e essa dimensão é relevante para esta sinalização. Uma vez que, no parque, existem inúmeros aspectos contraditórios no âmbito legal, como, por exemplo, a presença da comunidade em uma unidade de conservação de proteção integral, explicitar e discutir o contexto e pertinência da legislação e a importância da sociedade organizada para atuar junto dos tomadores de decisão e órgãos de controle social poderiam estar entre os objetivos das atividades. O fato de estas comunidades lutarem pela sua permanência é uma oportunidade para ilustrar e refletir sobre a importância de movimentos coletivos. Nessa mesma linha, trazer o histórico e os problemas da delimitação da área do parque e todas as consequências para as comunidades tradicionais e para a conservação da biodiversidade são estratégias para desenvolver uma educação ambiental crítica nas atividades realizadas no núcleo.

Em uma análise geral, a tendência crítica foi predominante nas observações realizadas (Quadro 4). A predominância dessa tendência pode estar relacionada ao público participante das atividades - todos universitários e a maioria interessada em discutir os temas controversos dentro do parque. Contudo, este estudo nos permitiu identificar que essa abordagem pode ser desenvolvida nas unidades de conservação. Certamente, incorporar toda a complexidade das questões ambientais em atividades de curto prazo e com públicos variáveis é bastante desafiador. Por isso, ao apresentarmos e discutirmos os resultados que encontramos nesta pesquisa, esperamos contribuir com o planejamento e desenvolvimento de ações educativas nas unidades de conservação, assumindo que a abordagem crítica da educação ambiental é a mais apropriada para a busca das transformações socioambientais que desejamos.

Quadro 4. Predominância das tendências da educação ambiental em atividades desenvolvidas no Núcleo Picinguaba do Parque Estadual da Serra do Mar, relacionada às três dimensões da prática educativa

\begin{tabular}{|c|c|c|c|c|c|}
\hline Atividades/dimensão & PI1 & PI2 & TP1 & TP2 & TM1 \\
\hline Conhecimentos & Crítica & Crítica & Crítica & Crítica & Crítica \\
\hline Valores éticos e estéticos & Crítica & Crítica & Silenciosa & Crítica & Silenciosa \\
\hline Participação política & Crítica & Crítica & Silenciosa & Crítica & Silenciosa \\
\hline Geral & Crítica & Crítica & Silenciosa & Crítica & Silenciosa \\
\hline Atividades/dimensão & TM2 & \multicolumn{2}{|l|}{ RC1 } & RC2 & Total \\
\hline Conhecimentos & Crítica & \multicolumn{2}{|l|}{ Crítica } & Crítica & Crítica \\
\hline Valores éticos e estéticos & Crítica & \multicolumn{2}{|l|}{ Crítica } & Crítica & Crítica \\
\hline Participação política & Silenciosa & Silenciosa & \multicolumn{2}{|c|}{ Silenciosa } & Silenciosa \\
\hline Geral & Crítica & Crítica & \multicolumn{2}{|c|}{ Crítica } & Crítica \\
\hline
\end{tabular}

PI1 e 2 = palestra inicial; TP1 = trilha dos poços guiada por monitor 1; TP2 = trilha dos poços guiada por monitor 2; TM1 e 2 = trilha do manguezal; RC1 e 2 = roda de conversa; todas as atividades observadas por pesquisadoras 1 e 2 , respectivamente.

Fonte: elaborado pelas autoras. 
Em nossa análise, também observamos uma variação das tendências da educação ambiental entre as atividades desenvolvidas. Somente a palestra inicial (PI) e a roda de conversa (RC) foram consideradas predominantemente críticas pelas duas pesquisadoras. Esses tipos de atividade proporcionam um espaço de interação propício para discussões mais aprofundadas. Enquanto que as trilhas interpretativas têm uma dinâmica que comumente não propicia o diálogo, além de o próprio público se colocar em uma postura mais passiva do que participativa. Porém, duas trilhas (TP2 e TM2) apresentaram a tendência crítica como predominante. A TP propiciou um espaço de maior reflexão sobre a relação do ser humano com o ambiente pela presença da comunidade local. Um dos monitores não explorou esse potencial (TP1), enquanto o outro abordou as informações apresentadas durante o percurso de maneira crítica. Dessa forma, notamos que a intencionalidade das/os educadoras/es ambientais é essencial para uma abordagem crítica nas atividades. Mesmo que a área natural não apresente um potencial explícito, como no caso da TM, todos os temas podem ser abordados e problematizados de maneira que se articule uma visão integrada do meio ambiente (PACHECO-MUÑOZ, 2002). Cabe ressaltar que TM1 e TM2 se referem a uma única trilha, guiada por um mesmo monitor. Assim, as tendências atribuídas aos parâmetros são mais homogêneas, sendo que as diferenças registradas são devidas às subjetividades das investigadoras.

Nessa mesma linha de pensamento, Carvalho (2006) comenta que, se as dimensões dos conhecimentos, dos valores éticos e estéticos e da participação política forem tratadas de forma isolada, ou se uma delas for enfatizada em detrimento das outras, a prática educativa torna-se pouco efetiva. Uma sugestão para que essa articulação aconteça, seria propor, aos grupos de visitantes, que participem das diversas atividades oferecidas pelo parque, ou seja, trilhas mais voltadas aos aspectos ecológicos e atividades mais voltadas aos aspectos sociais e políticos, como visita à comunidade local e roda de conversa com morador local. Assim, a/o visitante poderia ter uma visão mais ampla das variáveis e desafios da questão ambiental.

\section{Conclusões}

Esse estudo mostrou o grande potencial das unidades de conservação em desenvolver atividades de educação ambiental que abordem a complexidade da conservação da biodiversidade de forma crítica, incentivando a reflexão e ação das/os participantes diante das questões ambientais. Quase todos os parâmetros analisados, com exceção de apenas um, receberam apontamentos da tendência crítica da educação ambiental. A proposta de se planejarem as ações de educação ambiental a partir das dimensões dos conhecimentos, dos valores éticos e estéticos e da participação política é muito pertinente ao contexto das unidades de conservação, pois incentiva o trabalho com a complexidade da questão ambiental, por meio de variadas estratégias metodológicas, aproveitando, dessa maneira, todo o potencial desse espaço educador. Nesse sentido, os procedimentos que utilizamos para realizar essa pesquisa podem servir como base para o planejamento e a avaliação de ações educativas em unidades de conservação ou em outras realidades. Ao mesmo tempo, notamos que este instrumento pode se tornar reducionista, se apenas uma classificação simplificada em tendências da educação ambiental for considerada. Dessa forma, vislumbramos o uso produtivo deste roteiro de análise condicionado a adaptações aos contextos específicos de cada local e aos objetivos, parâmetros e princípios adotados pela equipe responsável, e, ainda, a uma análise crítica dos resultados. 


\section{Agradecimentos}

Agradecemos ao Conselho Nacional de Desenvolvimento Científico e Tecnológico (CNPq), pela bolsa de mestrado concedida à primeira autora do trabalho; à Coordenadoria de Aperfeiçoamento de Pessoal de Nível Superior (CAPES), pela bolsa concedia à segunda autora do trabalho; ao Prof. Dr. Victor Ranieri, a Anne Caroline Malvestio (Escola de Engenharia de São Carlos da Universidade de São Paulo, USP), pela contribuição na coleta dos dados em campo; a Flávia Navarro, Jaime Navarro, Wellington e demais pessoas que nos atenderam muito solicitamente no Núcleo Picinguaba do Parque Estadual da Serra do Mar, e à Comissão Técnico-Científica do Instituto Florestal (COTEC), pela autorização desta pesquisa.

\section{Referências}

BARBOSA, L. C. Políticas públicas de educação ambiental numa sociedade de risco: tendências e desafios no Brasil. In: ENCONTRO NACIONAL DA ANPPAS, 4., 2008, Brasília. Anais... Brasília: ANPPAS, 2008. Disponível em: < http://www.anppas.org.br/ encontro4/cd/ARQUIVOS/GT9-543-258-20080510223017.pdf>. Acesso em: 04 maio 2015.

BONOTTO, D. M. B. Contribuições para o trabalho com valores em educação ambiental. Ciência \& Educação, Bauru, v. 14, n. 2, p. 295-306, 2008. Disponível em: < http://dx.doi. org/10.1590/S1516-73132008000200008>. Acesso em: 04 maio 2015.

CARR, D. Moral values and the arts in environmental education: towards an ethics of aesthetic appreciation. Journal of Philosophy of Education, London, v. 38, n. 2, p. 221-239, 2004.

CARVALHO, I. C. M. A invenção do sujeito ecológico: sentidos e trajetórias em educação ambiental. 2001. 349 f. Tese (Doutorado) - Faculdade de Educação, Universidade Federal do Rio Grande do Sul, Porto Alegre, 2001.

CARVALHO, L. M. A. A temática ambiental e o processo educativo: dimensões e abordagens. In: CINQUETTI, H.; LOGAREZZI, A. (Org.). Consumo e resíduo: fundamentos para o trabalho educativo. São Carlos: EdUFSCar, 2006. p. 19-41.

CASELLATO, M. A.; HOLZHACKER, R.; FERNANDEZ, J. M. (Trad.). Redação sem discriminação: pequeno guia vocabular com dicas para evitar as armadilhas do sexismo na linguagem corrente. São Paulo: Textonovo, 1996. Versão com exemplos em português, inglês e espanhol do livreto diretrizes para uma linguagem não-sexista, da UNESCO.

DENZIN, N. K.; LINCOLN, Y. S. Introdução: a disciplina e a prática da pesquisa qualitativa. In: $\quad$ O planejamento da pesquisa qualitativa: teorias e abordagens. Porto Alegre: Artmed, 2003. p. 15-41.

FRANCA, N. (Coord.). Educação ambiental em unidades de conservação. Rio de Janeiro: Ibase, 2006. Disponível em: < http://www.ibase.br/userimages/ap_ibase_ educacao_01c.pdf $>$. Acesso em: 04 maio 2015. 
Potencial das atividades de uso público ...

FREIRE, P. Pedagogia da esperança: um reencontro com a pedagogia do oprimido. Rio de Janeiro: Paz e Terra, 1994.

Pedagogia da autonomia. São Paulo: Paz e Terra, 1997.

GARCÍA-GÓMEZ, J.; NANDO-ROSALES, J. Estrategias didácticas en educación ambiental. Málaga: Aljibe, 2000.

GRÜN, M. Ética e educação ambiental: a conexão necessária. Campinas: Papirus, 1996.

HAMÚ, D.; AUCHINCLOSS, E.; GOLDSTEIN, W. (Ed.). Recommendations on the role and impact of education and communication for protected areas management in Latin

America. In:

. Communicating protected areas. Cambridge: IUCN, 2004. p. 3-8.

Disponível em: <https://portals.iucn.org/library/efiles/edocs/2004-057.pdf>. Acesso em: 04 maio 2015.

IARED, V. G.; OLIVEIRA, H. T. Formação de valores estéticos e éticos e o cerrado. In: ENCONTRO DE PESQUISA EM EDUCAÇÃO AMBIENTAL, 7., 2013, Rio Claro.

Anais... Rio Claro, 2013. Disponível em: <http://www.epea.tmp.br/epea2013_anais/pdfs/ plenary/0104-1.pdf>. Acesso em: 5 jan. 2014.

Integration of distinct educating spaces and their potential for a more

comprehensive environmental education work. International Electronic Journal of

Environmental Education, Aksaray, v. 2, n. 2, p. 129-148, 2012. Disponível em: < http:/ /

www.iejeegreen.com/index.php/iejeegreen/article/view/40/35>. Acesso em: 04 maio 2015.

LAÇIN ŞIMŞEK, C. Investigation of environmental topics in the science and technology curriculum and textbooks in terms of environmental ethics and aesthetics. Educational

Sciences: theory \& practice, Istanbul, v.11, n. 4, p- 2252-2257, 2011. Disponível em:

<http://files.eric.ed.gov/fulltext/EJ962698.pdf>. Acesso em: 04 maio 2015.

LAYRARGUES, P. P. Crise ambiental e suas implicações na educação ambiental. In: QUINTAS, J. S. Pensando e praticando educação ambiental na gestão do meio ambiente. 2. ed. Brasília: IBAMA, 2002. p. 161-198.

Educação para gestão ambiental: a cidadania no enfrentamento político dos conflitos socioambientais. In: LOUREIRO, C. F. B.; LAYRARGUES, P. P.; CASTRO, R. S. Sociedade e meio ambiente: a educação ambiental em debate. São Paulo: Cortez, 2000. p. $87-155$.

LIMA, S. T. Trilhas interpretativas: a aventura de conhecer a paisagem. Cadernos Paisagem, Rio Claro, n. 3, p. 39-44, 1998.

LOUREIRO, C. F. B. Educação ambiental e gestão participativa na explicitação e resolução de conflitos. Gestão em Ação, Salvador, v. 7, n. 1, p. 37-50, 2004a.

. Educar, participar e transformar em educação ambiental. Revista Brasileira de Educação Ambiental, Brasília, n. 0, p. 13-20, 2004b.

MADUREIRA, M. S. P.; TAGLIANI, P. R. A. Educação ambiental não-formal em unidades de conservação federais na zona costeira brasileira: uma análise crítica. Brasília: IBAMA, 1997. 
MARIN, A. A.; OLIVEIRA, H. T.; COMAR, V. A educação ambiental num contexto de complexidade do campo teórico da percepção. Interciencia, Caracas, v. 10, n. 28, p. 616-619, 2003.

MARPICA, N. S. As questões em livros didáticos de diferentes disciplinas da quintasérie do ensino fundamental. 2008169 f. Dissertação (Mestrado em Educação) - Centro de Educação e Ciências Humanas, Universidade Federal de São Carlos, São Carlos, 2008.

MENDONÇA, R. Conservar e criar: natureza, cultura e complexidade. São Paulo: Senac São Paulo, 2005.

. Educação ambiental vivencial. In: FERRARO-JUNIOR, L. A. Encontros e caminhos: formação de educadoras(es) ambientais e coletivos educadores. Brasília: MMA, 2007. p. 117-130.

MENDONÇA, R.; NEIMAN, Z. À sombra das árvores: transdisciplinaridade e educação ambiental em atividades extra classe. São Paulo: Chronos, 2003.

MENGHINI, F. B.; MOYÁ-NETO, J.; GUERRA, A. F. S. Interpretação ambiental. In: FERRARO-JUNIOR, L. A. Encontros e caminhos: formação de educadoras(es) ambientais e coletivos educadores. Brasília: MMA, 2007. p. 209-218.

MORELLO, J. H.; PENGUE, W. A. Economía ecológica y biodiversidad: um efoque desde el sur. Realidad Economica, Ciencia y Sociedad, Buenos Aires, n. 173, p. 149-154, 2000.

MORIN, E. Educar na era planetária: o pensamento complexo como método de aprendizagem no erro e na incerteza humana. São Paulo: Cortez; Brasília, DF: Unesco, 2003.

OLIVEIRA, H. T. (Bio)diversidade, sustentabilidade e solidariedade: conceitos centrais para a formação de educadores ambientais. In: SEMINÁRIO DE LA APEC, 9.: pluriculturalismo y globalización: produción del conocimiento para la construcción de la ciudadanía en latinoamérica, 2004, Barcelona. Actas... Barcelona: Asociación de Investigadores y Estudiantes Brasileños en Cataluña, 2004. p. 57-62.

PACHECO-MUNÕZ, M. F. Planeación educativa en los centros de recreación, educación y cultura ambiental. Tópicos en Educación Ambiental, Guadalajara, Mexico, v. 4, n. 10, p. 63-74, 2002. Disponível em: < http://www.anea.org.mx/Topicos/T\%2010/Paginas \%20 63-74.pdf>. Acesso em: 04 maio 2015.

QUINTAS, J. S. Educação no processo de gestão ambiental: uma proposta de educação ambiental transformadora e emancipatória. In: LAYRARGUES, P. P. Identidades da educação ambiental brasileira. Brasília: MMA, 2004. p. 113-140.

. Introdução à gestão ambiental pública. Brasília: IBAMA, 2002. 
SAMMARCO, Y. M. Educación ambiental y paisaje en los espacios naturales protegidos de Brasil: contribuciones a la construcción del documento Encea (Estrategias Nacionales de comunicación y EA para el SNUC). In: MEIRA CARTEA, P. A. et al. (Coord.). Educación ambiental: investigando sobre la práctica. Madrid: Organismo Autónomo Parques Nacionales, 2009. p. 202-225. Disponível em: <http://www.magrama.gob.es/es/ceneam/ recursos/documentos/investigando-practica_tcm7-270686.pdf $>$. Acesso em: 04 maio 2015.

Percepções socio-ambientais em unidades de conservação: o jardim de Lilith? 2005. 210 f. Dissertação (Mestrado em Engenharia Ambiental) - Universidade Federal de Santa Catarina, Florianópolis, 2005.

SÃO PAUlO (Estado). Secretaria do Meio Ambiente. Plano de manejo do Parque Estadual da Serra do Mar. São Paulo, 2006.

SAUVÉ, L. Uma cartografia das correntes em educação ambiental. In: SATO, M.; CARVALHO, I. C. M. Educação ambiental: pesquisa e desafios. Porto Alegre: Artmed, 2005a. p. 17-44.

Currents in environmental education: mapping a complex and evolving pedagogical field. Canadian Journal of Environmental Education, Thunder Bay, v. 10, n. 1, p. 11-37, 2005b. Disponível em: <http://files.eric.ed.gov/fulltext/EJ881772.pdf>. Acesso em: 04 maio 2015.

SENICIATO, T.; CAVASSAN, O. O ensino de ecologia e a experiência estética no ambiente natural: considerações preliminares. Ciência \& Educação, Bauru, v. 15, n. 2, p. 393-412, 2009. Disponível em: <http://dx.doi.org/10.1590/S1516-73132009000200010>. Acesso em: 04 maio 2015.

SILVA, R. L. F. O meio ambiente por trás da tela: estudo das concepções de educação ambiental dos filmes da TV Escola. 2007. 258 f. Tese (Doutorado em Educação) - Faculdade de Educação, Universidade de São Paulo, São Paulo, 2007.

SILVEIRA, E. A arte do encontro: a educação estética ambiental atuando com o teatro do oprimido. Educação em Revista, Belo Horizonte, v. 25, n. 3, p. 369-394, 2009. Disponível em: <http://dx.doi.org/10.1590/S0102-46982009000300018>. Acesso em: 04 maio 2015.

SISTEMA Nacional de Unidades de Conservação da Natureza - SNUC: texto da lei 9.985, de 18 de julho de 2000; decreto nº 4.340, de 22 de agosto de 2002. 5. ed. Brasília: MMA, 2004.

SORRENTINO, M.; FERRARO-JÚNIOR, L. A.; MARCON, M. M. R. Environmental education (EE) and restoration of degraded areas: public policies committed to diversity. In: RODRIGUES, R. R.; MARTINS, S. V.; GANDOLFI, S. (Ed.). High diversity forest restoration in degraded areas: methods and projects in Brazil. New York: Nova Science, 2007. p. 207-222. 
TOZONI-REIS, M. F. C. Introdução. In: Educação ambiental: natureza, razão e história. Campinas: Autores associados, 2004. p. 3-25.

TRISTÃO, T. Tecendo os fios da educação ambiental: o subjetivo, o coletivo, o pensado e o vivido. Educação e Pesquisa, São Paulo, v. 31, n. 2, p. 251-264, 2005. Disponível em: <http:/ /www.scielo.br/pdf/ep/v31n2/a08v31n2.pdf>. Acesso em: 04 maio 2015.

VALENTI, M. W. Educação ambiental e biodiversidade em unidades de conservação: mapeando tendências. 2010. 97 f. Dissertação (Mestrado em Ecologia e Recursos Naturais) Centro de Ciências Biológicas e Saúde, Universidade Federal de São Carlos, São Carlos, 2010.

WALS, A. E. J. (E.). Environmental education and biodiversity. Wageningen: National Reference Centre for Nature Management, 1999. 